International Union of History and Philosophy of Science Division of Logic, Methodology and Philosophy of Science THE 11TH INTERNATIONAL CONGRESS OF LOGIC, METHODOLOGY AND PHILOSOPHY OF SCIENCE

LOGIC

will be held in Cracow, Poland, August 20-26, 1999.

\title{
CONGRESS SECTIONS
}

1. Proof Theory (Chair: S. Buss)

2. Model Theory (Chair: W. Hodges)

3. Recursion Theory (Chair: Y. Moschovakis)

4. Axiomatic Set Theory (Chair: A. Louveau)

5. Logic and Computation (Clsair: J. Tiuryn)

6. Logic, Language and Cognition (Chair: M. Davies)

\section{GENERAL PHILOSOPHY OF SCIENCE}

7. Methodology (Chair: D. Papineau)

8. Probability, Induction, and Decision Theory (Chair: B. Skyrms)

PHILOSOPHICAL PROBLEMS ABOUT THE SCIENCES

9. Philosophy of Logic, Mathematics, and Computer Science (Chair: C. Parsons)

10. Philosophy of the Physical Sciences (Chair: J. Faye)

11. Philosophy of the Biological Sciences (Chair: G. Wolters)

12. Philosophy of Cognitive Sciences and Artificial Intelligence (Chair: C. Habel)

13. Philosophy of Linguistics (Chair: J. Hurford)

14. Philosophy of the Social Sciences (Chair: D. Sperber)

ETHICAL, HISTORICAL, AND SOCIAL PERSPECTIVES ON PHILOSOPHY

OF SCIENCE

15. Ethics of Science and Technology (Chair: L. Bergström)

16. History of Logic, Methodology, and Philosophy of Science

(Chair: H. Ishiguro)

17. Philosophy of Questions Raised by the History and Sociology of Science

(Chair: S. Gaukroger)

\section{ABSTRACTS}

Abstracts of contributed papers should be submitted before February 1st, 1999. Send 3 hard copies and an electronic version converted to Word for Windows or LTEX2 $\epsilon$ on a diskette formatted for DOS. The abstract should include the number and the title of the relevant section, the title of your paper, and your name and address - all centered. It must not exceed 2 pages (printed area per page: width 12 $\mathrm{cm}$, length $18 \mathrm{~cm}$, font: Times Roman, $10 \mathrm{pt}$; line spacing 1.5 ; no page numbers). Further information from: Organizing Committee LMPS 99, Instirute of Philosophy Jagiellonian University, Grodzka 52, PL 31-044 Cracow, Poland, tel/fax +48124224916

email: Imps99@jetta.if.uj.edu.pl

www.uj.edu.pl/Phils/congress 